\title{
The barrier-free design of kindergarten buildings
}

\author{
Chengxingguo ${ }^{1, a}$, Gaohuali, b \\ ${ }^{1}$ School of Civil Engineering and Architecture, Liaocheng University, Shandong, China \\ ${ }^{2}$ School of Civil Engineering and Architecture, Liaocheng University, Shandong, China \\ achengxingguo@Icu.edu.cn, bgaohuali@Icu.edu.cn
}

Keywords: kindergarten, barrier-free design, barrier-free system, universal design

\begin{abstract}
The paper summarized the present situation of barrier-free design of kindergarten in china and pointed out some deficiencies by studying on children's physical, psychological and behavioral characteristics, then explored the barrier-free system.
\end{abstract}

\section{Barrier-free design}

Definition, purpose and principle. The United Nations Organization put forward the conception of Barrier-free design in 1974, which aimed at eliminating barriers in the environment and product design for all disabled people. The goal of barrier-free design is to achieve accessibility in the physical environment, information exchange and human environment for people with disabilities. Broadly speaking, Barrier free design is to create a more safe, convenient and equal participation for all people. It's not only beneficial to disabled people, but also conducive to the elderly, children, women and all those with mobility problems.

The principle of accessible design is determined by the relevant norms, not the same in all countries. Generally accepted principles:

1)The principle of global: In the design only consider one aspect or a part of the barrier-free is less effective, it not only can't provide the convenience of life for people with disabilities, but will increase construction costs and become unsightly furnishings.

2) People-oriented principle: The end-user of the barrier-free design is all types of people, including people with disabilities. We should consider the basic demands of residents, make every effort to achieve convenience, safety and comfort, fully embody the "people-oriented" concept.

3) Principle of Sustainable Development: Nursery design should be flexible, able to adapt to the future development direction, to facilitate the conversion or transformation, to ensure the long period of time to meet the needs of users.

In addition, professor Ronald L Mace put forward the most representative seven principle, in general design as the center, which including equitable use, flexibility in use, simple and intuitive, perceptible information, tolerance for error, low physical effort, size and space for approach and use.

The content of the kindergarten building barrier-free design. Barrier-free design including road, building and information barrier-free. Road Accessibility is concerned that the construction of roads, city squares, boulevards, parks, walking the streets, bus stations, rail transit stations, pedestrian bridge (Road), parking lots and other barrier-free facilities. The kindergarten barrier-free design for key parts of including building entrances, Level channel, vertical transportation, the bathroom, bathroom, telephone, children activity room, outdoor access, barrier-free marks etc.

\section{The design of the kindergarten}

The physical, psychological, behavioral characteristics of Children. The kindergarten is mainly for $3 \sim 6$ years old children. The physiological, psychological and behavior are all in the original human stage of development. Their space needs and feelings are different with adults. These features are the main consideration factors in the design.

Children's way of thinking has obvious intuitive, they love imitation, lively, curious, like to play 
with the companions, has the rich body language. Specific image and lively environment tend to attract the attention of young children. They walk while playing, shouting and chasing. The ground is uneven or too smooth will bring dangerous. The staircase is too steep and on both sides there is no handrail will make them feel inconvenient. For children, it handles higher, and its doors overweight, etc, will bring them use inconvenience. Using the adult scale furniture and facilities also gave them the inconvenience.

The main points of the kindergarten building design.

1) The overall layout: Overall plan for kindergarten should be adapted to local conditions, functional area clear and easy be managed. Green should be combined with the requirements of the functions, features and architectural landscape, with the unified planning of building design and construction, fully reflects the characteristics of three-dimensional, ecological. Kindergarten should be a good building orientation, sunlight and ventilation.

2) Building: The kindergarten building should be a reasonable combination of architectural forms and styles and strive to reflect the children's characteristics.

The problems existing in the design. Studying the built kindergarten, there are following questions in barrier-free design:

1) Barrier-free idea to be further improved. From developers to the public, they all lack of the barrier-free consciousness. 2) A lack of grasp of the scale of the child. During the design process the designers emphasizes the children's scale, but did not consider the details. Such as Stairs too steep, door handles too high, the location and height settings of the drinking unreasonable. The bathroom floor is too smooth and too small for Children retrogression and turning. 3) Existing barrier-free facilities is not complete and less secure. Facilities are not sign or logo is not apparent, ramps no guardrail, toilet no arms. There is no entry in the lanes, and the width of the blind slope is not enough. 4) Under the pressure of the owner, design personnel executive barrier free facilities construction standards is not enough.

\section{The obstacle-free system of kindergarten}

\section{The design principles of kindergarten barrier-free.}

1) Safety: Safety is the first principles in the design. Firstly, the activity field and the surrounding environment should be safe and comfortable, such as safe road, water, facilities, etc; Secondly, activities of the game should be suitable for disabled children and health, appropriately increase auxiliary facilities, and provide resting places for teaching staff. Finally, furniture and facilities should choose to comply with safety standards, use toxic, blunt and soft material.

2) General design: The purpose of Barrier-free design is for all can use and enjoyment life. Meet the disabled children's needs, don't forget to improve children's needs.

3) Open: Communication is a kind of means which coordinate the relation between individuals, individuals and groups, group and group. An open space can help eliminate negative psychology, such as the loneliness, the loss and fear. Therefore, barrier-free design should meet the users in the basic biological and security needs, pay attention to create the open places, meet their psychological and spiritual demand.

4) Comprehensive: Children's activity places can't simply to be as sports venues, but should be comprehensive consideration, combined with the sure physical environment.

The barrier-free design of kindergarten's physical environment.

1) Tthe entrance: The main barrier is steps and the width of the door. The entrance of a building can not be set up steps, when must be set up, should build a ramp or lift. Door should be smooth, no sharp corners. Without the use of threshold, spring door or revolving door. More than one entrance and other main entrance should be set international traffic sign. According to the characteristics of children, attention the height, position, text size, color, brightness and guide method of the Logo figure .The width of the entrance door shall be not less than 1.20 meters. In order to ensure the safety, the door within 1.50 meters around the surface height should be avoided. Foyer ground should choose waterproof and anti-skid material.

2) Channel $\backslash$ corridor: Corridor width shall comply with the following standards: Teaching area 
with double rooms not less than 1.8 meters, single room not less than 1.5 meters. The channel which Children often enter should not be provided with steps, when necessary can be provided with non-slip ramp, the gradient should not be greater than 1: 12. The corner should be made into a curved surface, this will not only prevent the collision accident, but also can reduce the damage to the wall. If not do surface treatment, should be carried out corner protection.

3) The stairs, railings, handrails, steps shall conform to the following provisions: The stairs on both sides is provided with a double-layer armrest, height is not more than 0.90 meters and 0.65 meters respectively. Banister vertical line net distance shall be not more than 0.11 meters, when the stair well net width greater than 0.2 meters, must take safety measures. Stair step height should not exceed 0.15 meters, width of not less than 0.26 meters.

4) Rooms: Activity room, bedroom, sound physical activity room should be provided with double fan door, the width of not less than 1.20 meters. Window height from the ground not more than 0.6 meters, 1.3 meters from the ground does not set the casement window; window in children's activity area can not be placed objects that children can climb. Children in regular contact within the 1.3 meters following the indoor wall should not be rough. Wall, window, heating cover and other parts must be made into a small fillet. Children's furniture should be appropriate to the height of children, using environmentally friendly materials. Desktop length should ensure that every child in possession of 0.50-0.55 meters, a width of 0.35-0.50 meters. Bed between the channels shall be not less than 0.60 meters. If needed to use the bunk beds, to be equipped with fixed bunk beds, the total height should not be higher than 1.20 meters, located around a height of not less than 0.30 meters of the fence, and can only be placed along the wall. Indoor activity area must install leakage protection device, socket installed in out of reach of children.

5) Washrooms: Should be divided or separated, well-ventilated, and the ground should be non-slip and easy to clean. Wash basin height of 0.50-0.55 meters, width is $0.40-0.45$ meters, the tap spacing 0.35-0.40meters. Heat Preservation should have locking device. The toilet size is $0.8 \times 0.7$ meters, trench width is $0.16-0.18$ meters; toilet height is $0.25-0.3$ meters.

6) Facilities and equipment: Should adapt to the needs of children at different ages. Sand pool depth 0.3-0.5 meters, depth of water storage of not more than 0.3meters. Pool sand (no use of industrial sand) and water should be changed frequently and kept clean. Large and medium-sized sports equipment should be installed in soft ground. Prohibit the use of fully enclosed slides and channel. Ornaments on sports equipment can not block the sight of teachers and children. The medical and rehabilitation equipment and toys should be under the guidance of teachers.

The barrier-free design of information exchange environment. Information accessibility refers to any person in any case equally easy access to information and use of information. Accessibility of the kindergarten information environment is mainly reflected in

the entrances to set up signs that eye-catching and easy to understand, voice prompt system, route directional signs. Realization of communication barrier-free, should adopt the open teaching, and to allow different age groups of children to play together. The use of open space form to ensure that each class can freely communication. Effort to promote free contact, spatial proximity, cooperative games and visual communication so that all kinds of activities in the natural state.

The barrier-free design of humanistic environment. The humanistic environment is the social environment corresponding to the natural environment, which contains the thought, idea, belief, culture and other aspects. The realization of humane environment of barrier-free design, should do the following: First, we must establish a correct concept of barrier free. The development of the concept of barrier-free environment depends on the whole of human society on disabled people's attitude. Love without obstacles, the full understanding and care for of others, we can create a full understanding, friendship, mutual aid spirit of humane space. Second, make laws to ensure that person with disabilities and the rights of vulnerable groups. Third, actively promote the disabled person's welfare policy, safeguard their rights and interests. In addition, the accessibility of the human environment also includes culture, sports, recreation and other aspects.

\section{Conclusion}


Barrier-free construction is a systematic project, which requires coordination and cooperation of all sectors of society, "Accessibility" requirement embodied in the kindergarten of the functional design, layout, decoration, pipeline layout, building facilities and equipment, and furniture design. Barrier-free construction is from the material level of barrier-free facilities, gradually shift to the social spirit, a full range of accessibility, so as to achieve the three-dimensional, all-round social construction of barrier-free environment. Related to the educational environment of the kindergarten should be so.

\section{References}

[1] Lizhimin. Song ling, Barrier-free Architectural Environmental Design, 2011.01

[2] Lizhitao. the kindergarten architectural design, Beijing, china architecture \& building press 2006.07

[3] Codes for Design ON Accessibility of Urban Roads and Buildings, JGJ 50-2001

[4] Mark Dudek. Kindergarten Architecture. Spon Press,2000

[5] Smith. T. E. C., Polloway E. A., Patton, J. R., \& Dowdy, C. A. (2001). Teaching students with special needs in inclusive settings( 3th ed.). Boston, Allyn \& Bacon

[6] Information on A+U

[7] Information on Architecture Journal

[8] Information on The Architect 